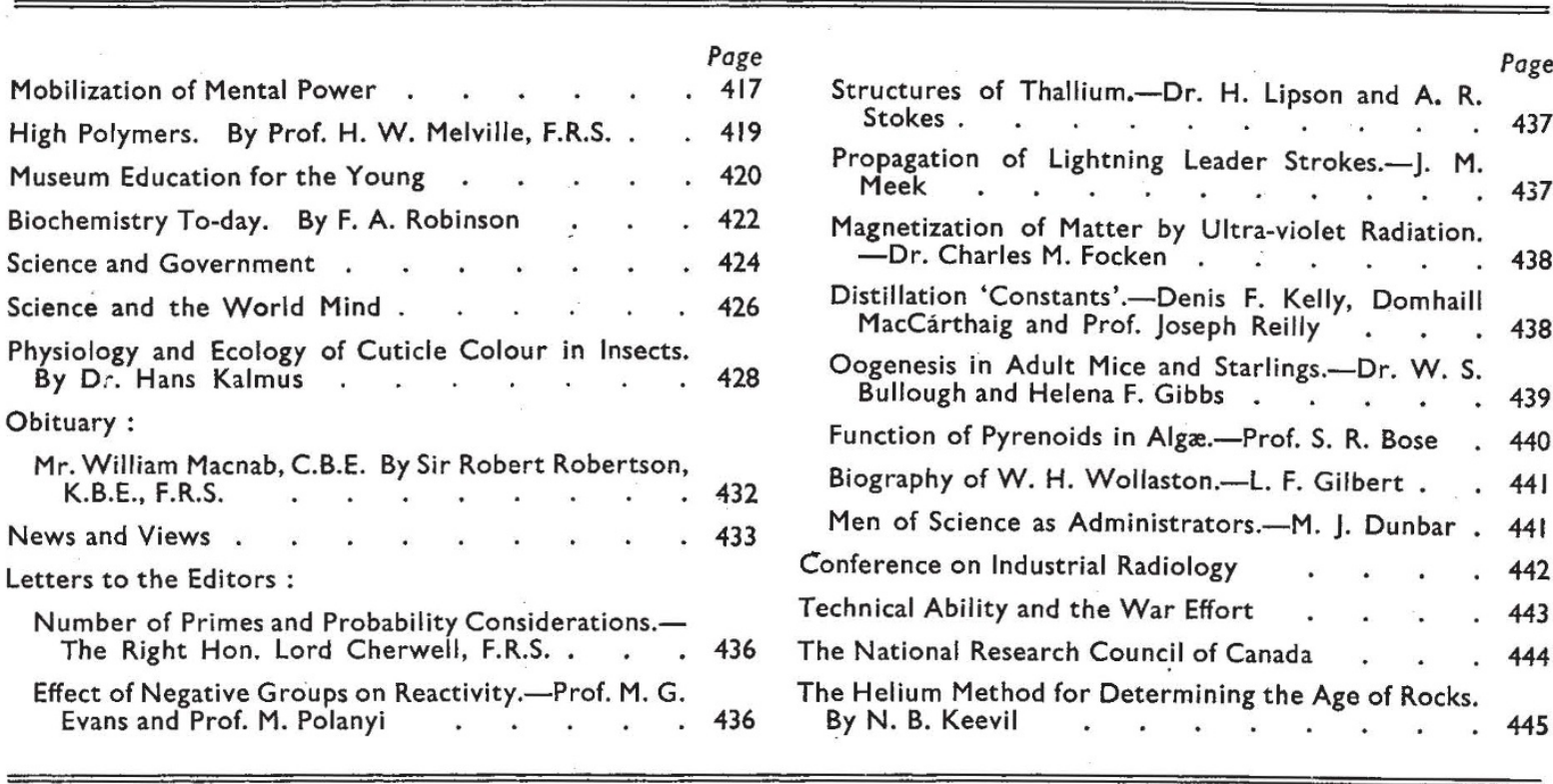

\title{
MOBILIZATION OF MENTAL POWER
}

T HE relatively late rise of psychology among the sciences is partly due to the fact that its subject-matter is so wrapped in prejudice and entangled in tradition that it is most difficult to examine in a detached and scientific spirit. The obstacles preventing the application of precise psychological information to personnel selection in the army, where tradition is so deeply entrenched, would seem to be particularly forbidding, and the Select Committee on National Expenditure is to be congratulated for devoting one of its reports to this topic*.

One immediate effect of the introduction of intelligence tests in the United States Army in 1917 was the discharge of about eight thousand men on account of mental defect, the transference of about ten thousand to labour battalions and the recommendation that a further ten thousand required special training which would allow for their low ability. Since the War of 1914-18, the measurement of intelligent behaviour has made notable advances both in theory and practice (although, judging by conditions in contemporary society, a parallel progress is far from evident in the trait to be measured), and it can confidently be anticipated that the outcome of a major testing programme carried out now would involve results of great consequence.

* Twenty-Second Report of the Select Committee on National Expenditare. (London: H.M. Stationery Office, 1941.)
In spite of the increase in mechanization, it still remains true that the human element in warfare is, in the long run, more important than technical devices. A necessary condition of the efficiency of any mechanism, organism or organization is that every component should be optimally situated in relation to the whole. To each constituent part should be assigned its most appropriate function. For society to attain that stage of efficiency so essential in total war, full use should be made, so far as is humanly possible, of all the native ability and skill, all the training and qualities of personality that are available. In so far as we fall short of this objective, to that extent are we inefficient. It is, of course, assumed that the supply of talent, innate and acquired, should be related to the military and civilian needs of the nation at war.

The review by Dr. C. S. Myers in Nature of May 10, 1941, of the applications of psychology already achieved in the present War, indicated the many possibilities of utilizing psychological methods in the Fighting Services and industry. Several examples were quoted in which individuals had utilized such methods, but there is little sign that those in authority regard them as more than interesting experiments.

The report of the Select Committee recognizes that many mental tests in use until now have not fulfilled the selective functions for which they were presumably designed. No doubt this can be 
attributed partly to the extended use of verbal rather than perceptual and performance tests. Apart from the existing evidence, which points to a verbal factor orthogonal to intelligence, the use of verbal tests puts schooling at a premium and does not effectively discriminate between the native ability of persons differing widely in educational background, as must be the case in a conscript army.

It is unfortunate that the outworn idealistic belief that abilities are mere entities seated in the mind still makes its influence felt in test construction. A more realistic approach is desirable. So far as the Services are concerned, the guiding principle should be the need for selecting persons capable of performing the tasks required by the more specialized units of the armed Forces. The ability should be defined by the test, not the test by the ability ; and the design of the test should, in general, be determined by the activities called into play in the actual performance of the work for which selection is needed.

The elimination of feeble-minded and backward soldiers before money and training have been wasted upon them ought to present no difficulty; tests are available, specially built to deal with these problems. But the careful segregation or placing of neurotic types needs the employment of a new kind of criterion. The Committee's recommendation that the Ministry of Labour and National Service should, in future, not be responsible for posting men to any particular corps but only to the army as a whole, will it is hoped, be put into effect with as little delay as possible.

The suggestion that the testing should rest entirely in the hands of Service personnel is open to criticism. It needs to be stressed that so far as possible the testing in all its stages should be under the control and supervision of qualified psychologists, with a status similar to that of the existing medical boards. Otherwise, the scheme is likely to defeat its own ends. Serious, defects in the conditions of administration of the tests can invalidate the results, as may happen if the work is entrusted to officers who have only been given some slight instruction in the preliminaries of testing. The following instances taken from a mechanized unit are instructive. An officer charged with the administration of the tests was accustomed to inform the candidates, after imparting other misleading information, that "they all had an equal chance of doing equally well on the tests", which is the very opposite of the truth. The period immediately prior to the testing was frequently spent, 'on the square' and the men were consequently in various stages of fatigue. No account seems to have been taken of poor health at the time of the test. Furthermore, a well-intentioned sergeant apparently always did his best to assist the men in the test; he thought it was the correct thing to do. Copying also went on.

The advantages that would have followed the introduction of scientific methods of selection before or at the outbreak of war will, it seems, be largely obviated because the bulk of the men in the Forces have already received their training and, in the present circumstances of war, transfers on a large scale are considered undesirable. This is recognized by the Select Committee. However, if it is too late in one sphere, the moment is opportune to begin in another. Now is the time to sort out the thousands of youths that have joined the Air Training Corps. Here it is possible, with the aid of psychological tests, to achieve a great economy in time and expense by providing a differential training according to capacity and temperament.

The sphere in which purely psychological criteria of selection, in addition, of course, to physiological tests, could reap their greatest reward is probably that of pilot selection. Now, while there is no reason to question that the medical authorities have availed themselves of the best diagnostic techniques, there are grounds for believing that the possible contributions which psychology has to offer in this urgent field have by no means been fully explored. No effort should be too great to select, with the utmost care, the relatively small number of future pilots out of a much larger number of candidates. It is here that, added to the minimum requirements of intelligence, the qualities of temperament and character exert their most crucial effects. The problems are exceedingly complex. Nevertheless, the traits subserving mental stability, persistence, prolonged attentive power or the capacity to respond rapidly to a succession of surprise stimuli, to mention a few, should not wholly elude measurement. Those characteristics by which a day fighter pilot may be discriminated with a maximum of accuracy from the night fighter pilot and both from the bomber pilot merit all the resourcefulness and imagination in psychological measurement which are available.

The use of diagnostic criteria of ability in the selection and promotion of officers is also advocated by the Select Committee. It would be interesting to know how this would affect the existing distribution of ability among the commissioned ranks. However, given a certain level of intelligence, stress is laid in the report upon qualities of personality, and new experimental methods of assessing the relevant qualities are urgently needed. The system of promotion by seniority, wherever it is employed, is not necessarily calculated to elevate to posts of greater responsibility those men who are distinguished by superior 
talents. If anything, increase in age beyond a certain point is probably inversely correlated with many of the qualities which make for success as a soldier. An officer, as a result, let us say, of bravery in the field, may be given a post in which matters relating to strategy are decided by him. But it cannot be assumed that the biological and social factors which operate to select for the quality of courage are the same as those which select for the traits which make a good strategist. Other considerations, which arise wherever appointments are to be determined by experience or by more direct estimates of capacity, also deserve weight. It may happen that a soldier with considerable military experience is entrusted with a high post mainly on this ground ; but what is really relevant is the capacity to profit from experience rather than the mere fact of having had experience, and the appointment should be determined at least as much by the former as by the latter.

The scope of psychological methods in the organization of war is not confined to the application of mental tests in the Services. The allocation of new labour in industry, the human element in production, propaganda, morale and evacuation are some of the problems the solution of which would be facilitated were the aid of psychology more fully enlisted. The greatly increased number of trained psychologists which would be required could probably be provided by the Central Register, with the added advantage that the special qualifications of many able research workers in psychology would be utilized to the best advantage. It is to be hoped that the Select Committee will be able to turn its attention to these wider applications of psychology.

\section{HIGH POLYMERS}

Collected Papers of Wallace Hume Carothers on High Polymeric Substances

Edited by Prof. H. Mark and G. Stafford Whitby. (High Polymers, Vol. 1.) Pp. xix +459 . (New York: Interscience Publishers, Inc.; London: H. K. Lewis and Co., Ltd., 1940). 8.50 dollars; 5ls. net.

Physical Chemistry of High Polymeric Systems By Prof. H. Mark. Translated from the manuscript by K. Sinclair, revised by J. Edmund Woods. (High Polymers, Vol. 2.) Pp. $x+345$. (New York: Interscience Publishers, Inc.; London: H. K. Lewis and Co., Ltd., 1940.) 6.50 dollars; 39 s. net.

T $\mathrm{T}$ is impossible for one author to attempt to bring 1 within the compass of one or even a series of volumes a comprehensive and authoritative account of high polymer systems. Nothing less than a carefully chosen team of experts will suffice for the task. While the subject has come more and more into prominence in recent years this is only partly due to new knowledge of synthetic polymers, for there has accumulated over a considerable period an extensive and often unco-ordinated body of knowledge of the natural high polymers, rubber, cellulose, proteins and the like. Gradually, however, the whole subject has been cleared of indefinite opinions and conceptions, and some degree of order introduced into this branch of chemistry. This does not mean that all the fundamental problems are solved, and it is now only a question of settling matters of insignificant detail. Much has yet to be done, and a first step in the process is a clear survey of the existing state of affairs. This is the object of the editors-R. E. Burk, H. Mark and G. S. Whitby-in the volumes under review.

Appropriately enough the first volume of the series comprises the collected papers of the late W. H. Carothers. It is difficult to realize that in the short space of nine years Carothers not only contributed handsomely to the subject of polymers but also brought into being two well-known plasties of unique properties-'Nylon' and 'Duprene' (polychloroprene). In these collected papers we see the train of thought which led to the discovery of these substances. Their discovery was no idle shot in the dark or the outcome of a lucky experiment. It was the result of a most painstaking and systematic search at a time when intuition played a large part. In his first paper, Carothers clears the ground by considering in general the theory underlying the formation of condensation polymers; that is to say, it is an attempt to predict whether bifunctional molecules will react inter- or intramolecularly. On this basis an examination is made of those molecules which form polymers, but it is soon shown that the molecular weights of the products are rather low to be of interest from the plastic point of view. The matter is not left there, for it is realized that higher polymers may be formed only if the reaction is finally carried to completion in a molecular still. At this stage molecular weights of the order of 10,000 become a practical proposition, and thereby the prospect of obtaining synthetic fibres of sufficient strength immediately presents itself. Carothers carries the 